\title{
The Contextual Meaning of Japanese Setsuzokushi
}

\author{
Septrian Adhi Saputro ${ }^{1}$, Idah Hamidah ${ }^{2}$, Dian Bayu Firmansyah ${ }^{3}$ \\ Universitas Jenderal Soedirman, Purwokerto, Jawa Tengah, Indonesia \\ Universitas Jenderal Soedirman, Purwokerto, Jawa Tengah, Indonesia \\ Universitas Jenderal Soedirman, Purwokerto, Jawa Tengah, Indonesia
}

\begin{tabular}{l}
\hline Article History \\
\hline Submitted date: \\
2021-02-18 \\
Accepted date: \\
2021-05-27 \\
Published date: \\
2021-05-31 \\
\hline Keywords:
\end{tabular}

\section{Keywords:}

Conjunction; noni; kuseni; contextual meaning; Japanese setsuzokushi

\section{Abstract}

This study describes the contextual meaning of the noni and kuseni conjunctions in the drama dialogue Dragon Zakura. This study uses a qualitative paradigm with syntactic and semantic research approaches. The research data source is a Japanese drama entitled Dragon Zakura with data in conversational sentences. There is noni or kuseni conjunction, which is collected through the 'simak-catat' technique. Through Makino (1994) and Chandra (2009)'s concept of noni and kuseni, data are interpreted using contextual meaning. The results of this study indicate that the noni and kuseni conjunctions are included in gyakusetsu no setsuzokujoshi. The two conjunctions, namely noni and kuseni, although they have similarities in stating the contradiction between two things, namely between what the speaker thinks/suspected/should have, and the facts that occur, noni is more broad and objective. Noni can express negative feelings, such as disappointment, criticism, and frustration, but can also express neutral or positive emotions, such as admiration. Meanwhile, kuseni are only used to describe the speaker's negative feelings, such as criticism, annoyance, and disappointment.

\section{Kata Kunci:}

konjungsi; noni; kuseni; makna kontekstual; kata sambung bahasa Jepang

\section{Abstrak}

\section{Makna Kontekstual Setsuzokushi Bahasa Jepang}

Penelitian ini bertujuan untuk mendeskripsikan makna kontekstual konjungsi noni dan kuseni dalam dialog drama Dragon Zakura. Penelitian ini menggunakan paradigma kualitatif dengan ancangan penelitian sintaksis dan semantik. Sumber data penelitian berupa drama berbahasa Jepang, berjudul Dragon Zakura dengan data berupa kalimat percakapan yang di dalamnya terdapat konjungsi noni atau kuseni, yang dikumpulkan melalui Teknik simak-catat. Melalui konsep Makino (1994) dan Chandra (2009) tentang noni dan kuseni, data diinterpretasi menggunakan konsep makna kontekstual. Hasil penelitian ini menunjukkan bahwa konjungsi noni dan kuseni termasuk dalam gyakusetsu no setsuzokujoshi. Kedua konjungsi, yaitu noni dan kuseni, meskipun mempunyai persamaan dalam menyatakan pertentangan antara dua hal, yakni antara yang dipikirkan/diduga/seharusnya menurut pembicara dan fakta yang terjadi, noni lebih bersifat luas dan objektif. Noni dapat mengungkapkan perasaan negatif, seperti kekecewaan, kritikan, dan kekesalan, namun juga dapat mengungkapkan perasaan netral maupun positif, seperti kekaguman. Sementara kuseni hanya digunakan untuk mengungkapkan perasaan negatif pembicara, seperti kritik, kesal, dan kecewa.

Corresponding author:

${ }^{1}$ septrianshi@gmail.com

2 Idahhamidah.75@yahoo.com

3 dbayuf@unsoed.ac.id 


\section{Pendahuluan}

Bahasa merupakan alat utama untuk yang dibutuhkan oleh manusia untuk berkomunikasi dengan orang lain. Setiap bahasa memiliki berbagai macam bentuk pola kalimat yang dapat disusun agar menjadi padanan yang tepat. Untuk itu, diperlukan kata penghubung. Kata penghubung atau kata sambung dalam bahasa Jepang disebut dengan setsuzokushi (kata sambung). Isami dalam Sudjianto (1996, p. 100) menjelaskan bahwa setsuzokushi adalah kelas kata yang dipakai untuk menghubungkan atau merangkaikan kalimat dengan kalimat atau merangkaikan bagian dengan bagian. Jika memahami penggunaan setsuzokushi dengan baik, maka pembelajar bahasa Jepang dapat mengetahui hubungan antarkalimat dengan kalimat sehingga dapat menyampaikan atau menerima informasi dengan baik.

Meskipun demikian, menurut Mulyadi (1999), setsuzokushi adalah salah satu jenis kata yang penting dan sulit untuk dipelajari, mengingat jumlahnya sangat banyak. Selain itu, setsuzokushi memiliki arti yang hampir sama, tetapi memiliki fungsi dan cara penggunaan yang berbeda. Oleh karena itu perlu adanya pemahaman mengenai penggunaan setsuzokushi.

Setsuzokushi dalam bahasa Jepang yang menyatakan hubungan berlawanan disebut dengan gyakusetsu no setsuzokushi (Arino, 1998; Chino, 1991; Kawashima, 1999). Gyakusetsu no setsuzokushi diperlukan untuk menghubungkan kalimat yang menyatakan berlawanan, karena dalam setiap komunikasi, pembicara tidak selalu sependapat dengan mitra bicara (Machawan, 2016; Ramadhani, 2018). Dalam bahasa Jepang, terdapat beberapa setsuzokushi yang menyatakan hal yang berlawanan, antara lain noni dan kuseni. Menurut Chandra (2009) noni digunakan untuk menunjukkan suatu hal yang bertentangan dengan hal yang telah disebutkan sebelumnya. Kemudian menurut Makino (1994) kuseni merupakan kata sambung yang mengekspresikan ketidaksukaan, kemarahan, dan ketidaksetujuan terhadap tingkah laku atau keadaan seseorang. Secara umum penggunaan noni dan kuseni memiliki arti yang sama. Kedua konjungsi tersebut menjelaskan hubungan yang saling berlawanan. Dalam bahasa Indonesia keduanya diartikan menjadi meskipun, walaupun, atau padahal (Matsuura, 1994).

Penelitian sebelumnya yang relevan dengan penelitian ini adalah penelitian Putri (2016) yang meneliti persamaan penggunaan nagara, noni, dan kuseni serta menganalisis apakah ketiga konjungsi tersebut dapat digunakan secara bergantian dalam kalimat yang sama atau tidak. Studi ini menyimpulkan bahwa kalimat yang menggunakan konjungsi nagara dan noni dapat diterapkan pada diri sendiri atau orang lain, sedangkan konjungsi kuseni hanya dapat diterapkan pada orang lain. Studi ini juga menemukan bahwa konjungsi nagara dan noni dapat menggantikan satu sama lain; Di sisi lain, konjungsi noni dan kuseni juga bisa saling menggantikan tetapi menghasilkan nuansa makna yang berbeda dalam kalimat. Ketiga konjungsi dapat saling menggantikan tergantung pada konteks kalimat. Kemudian dalam penelitian lain, Sari, dkk. (2017) meneliti perbedaan makna konjungsi ga dan demo, dua konjungsi yang menyatakan pertentangan, dalam cerpen Kusa Suberi karya Nagi Keishi. Studi ini menemukan bahwa konjungsi ga memiliki tiga arti: mengekspresikan dan kontradiksi absolut, menyatakan perbandingan makna, dan menyatakan perbedaan antara makna klausa. Konjungsi demo menunjukkan dua makna: pertentangan makna ideasional dengan kalimat sebelumnya dan keadaan apa yang dilakukan pembicara tanpa pengaruh kontekstual dari kalimat sebelumnya. Dalam dua penelitian tersebut meskipun terdapat persamaan dengan penelitian yang kami lakukan, terdapat perbedaan yang cukup signifikan. Penelitian ini lebih fokus pada makna kontekstual dalam arti, makna diberikan pada situasi saat konjungsi diungkapkan berdasar konteks yang melingkupinya. Konteks adalah sesuatu yang dijadikan rujukan atau menjadi latar dan dasar pembicaraan (Saifudin, 2018, 2019, 2020). 


\section{Metode Penelitian}

Penelitian ini merupakan penelitian deskriptif kualitatif. Penelitian deskriptif kualitatif menurut Bogdan dan Taylor yang dikutip dari Moleong (2010) yaitu prosedur penelitian yang menghasilkan data deskriptif berupa kata-kata tertulis/lisan dari orang-orang dan perilaku yang diamati.

Data yang digunakan untuk analisis dalam penelitian ini berupa kalimat yang mengandung konjungsi noni dan kuseni di dalam drama tersebut. Sumber data yang digunakan dalam penelitian ini adalah drama Dragon Zakura episode 1-10.

Teknik pengumpulan data yang digunakan pada penelitian ini adalah teknik simak dan teknik catat. Kemudian tahapan penulis dalam pengumpulan data adalah sebagai berikut.

1) Menonton berulang-ulang drama Dragon Zakura untuk mendapatkan data;

2) Mencatat waktu munculnya dialog atau kalimat yang berkaitan dengan noni dan kuseni.

3) Pemberian kode pada data yang telah didapatkan. Contoh kode yang digunakan adalah kode (DT/EP01/09:00) yang menandakan DT itu data, EP menandakan episodenya sedangkan 09:00 menandakan waktu munculnya kalimat atau dialog.

4) Mencatat atau memasukkan data yang telah diberi kode ke logbook agar lebih mudah dalam menganalisisnya.

Adapun dalam penyajian tulisan ini, hanya dianalisis perwakilan data sejumlah tujuh data yang merepresentasikan dari keseluruhan data yang diperoleh.

3 Hasil dan Pembahasan

Dari hasil analisis data, ditemukan bahwa penggunaan konjungsi nono dan kuseni adalah sebagai berikut.

Tabel 1. Penggunaan Konjungsi Noni dan Kuseni

\begin{tabular}{ll}
\hline \multicolumn{1}{c}{ Noni } & \multicolumn{1}{c}{ Kuseni } \\
\hline (1) Menyatakan perbandingan yang bertentangan & (1) Menyatakan kritikan \\
\hline (2) Menyatakan pertentangan atau & (2) Menyatakan hinaan atau sindiran \\
ketidaksetujuan & (3) Menyatakan ketidaksukaan/kekesalan \\
\hline (3) Menyatakan kekaguman & \\
\hline (4) Menyatakan kekecewaan &
\end{tabular}

Dapat diketahui dari tabel 1 bahwa kedua konjungsi pada umumnya dapat saling menggantikan mengingat keduanya menyatakan pertentangan. Perbedaan yang tampak adalah penggunaan konjungsi kuseni secara kontekstual bernuansa negatif, yakni kritikan, sindiran, dan kekesalan, sementara pada penggunaan konjungsi noni tidak hanya negatif, seperti contohnya dapat digunakan untuk mengungkapkan kekaguman.

\subsection{Penggunaan Noni}

\subsubsection{Menyatakan Perbandingan yang Bertentangan}

Data 1

となりの子はもう論理的思考の段階入ったのに、うちの子はまだだったか。

Tonari no ko wa mou ronriteki shikou no dankai haitta noni, uchi no ko wa mada dattaka.

'Padahal anak tetangga sudah memasuki tahap perkembangan pola pikir yang logis, akan tetapi

kenapa anak saya belum.'

Situasi:

Sakuragi sensei mengundang para orang tua murid di kelas khusus di sekolah untuk membahas ujian masuk Todai (Universitas Tokyo). Para orang tua murid tidak menaruh harapan sama sekali kepada anak-anaknya untuk dapat mengikuti ujian Todai karena selama ini mereka percaya bahwa anak-anaknya itu bodoh. Sakuragi sensei meyakinkan para orang tua bahwa anak-anaknya yang 
mengikuti les/kelas khusus yang dipimpin Sakuragi sensei benar-benar serius hendak menuju Todai, dan jika benar-benar mengikuti kelas khusus sampai akhir dan didukung para orang tua, maka mungkin saja anak-anaknya bisa masuk Todai. Akan tetapi, tetap saja para orang tua murid tidak mau yakin kepada anak-anaknya. Bahkan salah seorang ibu mengatakan bahwa ia mendidik dua anaknya yang kembar dengan cara mendidik yang sama sejak kecil, akan tetapi seiring anaknya dewasa, keduanya menunjukkan kemampuan yang berbeda, satu anaknya pintar, dan satu lagi bodoh sehingga menurut ibu tersebut akan percuma bagi si bodoh untuk berhasil meskipun ia belajar. Sakuragi sensei merasa pemikiran ibu tersebut salah dan menjelaskan suatu teori mengenai pemikiran anak yang dijelaskan dalam bentuk perbandingan, dan mengucapkan: "Tonari no ko wa mou ronriteki shikou no dankai haitta noni, uchi no ko wa mada dattaka ".

- Objek yang dibicarakan pada data 1: Pola pikir dua anak yang berbeda.

- Suasana hati pembicara: Netral, sedang menjelaskan suatu teori.

Analisis:

Pada data 1 konjungsi noni muncul di tengah kalimat sebagai bunnaka, melekat pada verba bentuk futsu kei (biasa) dalam bentuk lampau yaitu verba - ta haitta yang artinya 'masuk'. Konjungsi noni pada kalimat di atas memiliki makna perbandingan (taihi) digunakan penutur untuk membandingkan antara klausa tonari no ko 'anak tetangga' dan klausa uchi no ko 'anak saya'. Data 1, jika diartikan secara leksikal, atau arti per katanya maka berarti: Padahal anak tetangga sudah memasuki tahap perkembangan pola pikir yang logis, akan tetapi kenapa anak saya belum. Konjungsi noni pada kalimat tersebut artinya menjadi "padahal". Sedangkan secara kontekstual dalam konteks situasi dan objek pembicaraan, maka kalimat tersebut dapat diartikan menjadi : Meskipun ada anak yang sudah masuk pada tahap pemikiran logis, tetapi ada juga anak yang belum. Sehingga konjungsi noni secara kontekstual artinya menjadi "meskipun". Berdasarkan konteks situasi dan objek pembicaraan, Sakuragi sensei sedang menjelaskan teori suatu anak A yang berpikiran logis dengan anak $B$ yang berpikiran intuitif, yang menurutnya meskipun ada anak $A$ yang sudah berpikiran logis tetapi anak $B$ belum, hal tersebut tidak berarti bahwa anak A pintar sedangkan anak B bodoh. Konjungsi noni yang digunakan pada kalimat ini ditujukan untuk orang lain.

\subsubsection{Menyatakan Pertentangan atau Ketidaksetujuan}

Data 2

馬鹿みたい、無䭾なことしちゃって、あんなに東大にいけるわけがないのに。

Baka mitai, muda na koto shichatte, anna ni Todai ni ikeru wake ga nai noni.

'Bodoh sekali, melakukan hal yang sia-sia, padahal sudah jelas-jelas mustahil untuk masuk Universitas Tokyo.'

Situasi:

Sakuragi sensei membentuk sebuah kelas khusus untuk persiapan masuk Todai, dan sedang mengajarkan metode untuk mempermudah menghafalkan matematika melalui game. Kemudian murid-murid dari kelas lain penasaran dan datang untuk melihat kegiatan yang dilakukan oleh murid-murid di kelas khusus. Mizuno yang kebetulan lewat pun menjadi penasaran dan ikut melihat. Lalu sakuragi sensei menghampiri murid-murid yang melihat kegiatan yang dilakukan di kelas khusus dan mengajak untuk masuk ke kelas tersebut. Akan tetapi murid-murid langsung meninggalkan kelas begitu pun dengan Mizuno. Saat Mizuno meninggalkan kelas khusus, Sakuragi sensei menghampirinya dan berusaha membujuk dengan sangat persuasif agar dia ikut kelas khusus persiapan masuk Todai, akan tetapi Mizuno menolaknya dan meninggalkan Sakuragi sensei. Setelah meninggalkan Sakuragi sensei, Mizuno berkata "Baka mitai, mudana koto shichatte, annani Todai ikeru wake ga nai noni". 
- Objek yang dibicarakan pada data 2: Pilihan teman - temannya mengikuti kelas khusus untuk ujian masuk Todai.

- Suasana hati pembicara: Bertentangan, merasa tidak setuju atau memiliki keyakinan yang berbeda.

Analisis:

Pada data 2 konjungsi noni muncul pada akhir kalimat sebagai bunmatsu, melekat pada bentuk negasi - nai yaitu wake ga nai noni. Konjungsi noni pada kalimat tersebut digunakan sebagai kata sambung pada dua kalimat yang menyatakan bertentangan. Kalimat yang pertama yaitu 'melakukan hal yang sia-sia' dan kalimat kedua yaitu 'sudah jelas-jelas mustahil masuk Todai. Sehingga konjungsi yang tepat untuk dua kalimat yang bertentangan tersebut yaitu 'padahal'. Data 2 jika diartikan secara leksikal menjadi: bodoh sekali, melakukan hal sia-sia, padahal tidak ada alasan untuk masuk Todai. Sedangkan secara kontekstual dalam konteks situasi dan objek pembicaraan, maka kalimat tersebut dapat diartikan menjadi: "dia benar-benar bodoh, berapa kali harus kukatakan padanya aku tak mau masuk Todai". Konjungsi noni pada kalimat di atas memiliki arti "padahal", dan memiliki makna kontekstual bertentangan (gyakugen'in) karena pada kalimat tersebut Mizuno berfikir bahwa pilihan teman-temannya mengikuti les untuk persiapan masuk Todai merupakan pekerjaan bodoh yang sia-sia karena mau sekeras apapun belajar mereka tidak mungkin masuk Todai mengingat mereka berada di sekolah yang biasa saja. Bagi Mizuno tidak ada alasan untuk mengikuti kelas khusus. Konjungsi noni yang digunakan pada kalimat ini ditujukan untuk si pembicara sendiri (self talk).

\subsubsection{Menyatakan Kekaguman}

Data 3

叔母さん本当に変わちゃったんだな、昔は商売経験ぜんぜんなかったのに。

Obasan hontou ni kawachattandana, mukashi wa shoubai keiken zenzen nakatta noni.

'Bibi benar-benar telah berubah. Padahal dulu dia tidak berpengalaman dalam berdagang sama sekali.'

Situasi:

Yuusuke bersama Mizuno sedang mengobrol di pinggir kolam. Mizuno menanyakan alasan Yuusuke ikut kelas khusus, dia menjawab karena dia berhutang budi kepada Sakuragi sensei, sehingga dia mengikuti kelas khusus untuk membalas kebaikan dari Sakuragi sensei padanya. Kemudian Yuusuke bertanya kepada Mizuno mengenai ibunya yang akan menutup kedai dan mengubahnya menjadi tempat karaoke sambil berkata: "Obasan hontou ni kawachattandana, mukashi wa shoubai keiken zenzen nakatta noni".

- Objek yang dibicarakan pada kalimat: Obasan (Ibunya Mizuno), yang akan mengubah kedainya menjadi tempat karaoke.

- Suasana hati pembicara: kagum

Analisis:

Pada data 3 Konjungsi noni muncul di akhir kalimat sebagai bunmatsu, melekat pada negasi nai dalam bentuk lampau yaitu nakatta 'tidak', zenzen nakatta 'sama sekali tidak' menjadi zenzen nakatta noni. Data 3 jika diartikan secara leksikal menjadi: Bibi benar-benar berubah, padahal dulu dia tidak berpengalaman dalam berdagang sama sekali. Konjungsi noni pada kalimat tersebut memiliki arti "padahal" karena digunakan sebagai kata sambung antara kalimat "bibi benar-benar berubah' dengan 'dulu dia tidak berpengalaman dalam berdagang. Sedangkan berdasarkan konteks situasi, suasana hati dan objek pembicaraan, makna konjungsi noni pada kalimat tersebut berarti menyampaikan suatu hal yang di luar dugaan. Sama seperti makna leksikalnya, konjungsi noni secara konteks kalimat ini artinya "padahal". Hal ini adalah untuk menyampaikan maksud bahwa 
dugaan Yuusuke selama ini adalah dari dahulu Bibi (ibunya Mizuno) tidak memiliki pengalaman berdagang sama sekali, tetapi ia tidak menduga bahwa sekarang Bibi bahkan akan mengubah kedainya menjadi tempat karaoke, yang artinya saat ini ternyata Bibi sudah memiliki pengalaman/kemampuan berdagang. Hal ini tidak diduga oleh Yuusuke sebelumnya. Konjungsi noni yang digunakan pada kalimat ini ditujukan untuk mitra bicara/orang lain.

\subsubsection{Menyatakan Kekecewaan}

Data 4

昨日もう何度もメールをしたのに。

Kinou mou nandomo me-ru wo shitanoni.

'Padahal kemarin saya sudah berkali-kali mengirimkan pesan.'

\section{Situasi:}

Yuusuke dan Mizuno sedang berjalan dan mengobrol menuju ke ruangan kelas. Yoshino merasa tidak suka melihat Yuusuke dan Mizuno mengobrol, sedangkan dari kemarin ia mengirim pesan berkali-kali kepada Yuusuke tetapi tidak dibalas oleh Yuusuke. Kemudian tiba-tiba Yoshino muncul dan mengganggu pembicaraan Yuusuke dan Mizuno, mendorong Mizuno, dan kemudian berkata kepada Yuusuke: "Kinou mou nandomo me-ru wo shitanoni".

- Objek yang dibicarakan pada kalimat: Pesan-pesan yang dikirimkan

- Suasana hati pembicara: Tidak suka, kecewa

Analisis:

Pada data 4 konjungsi noni muncul pada akhir kalimat sebagai bunmatsu, melekat pada verba bentuk futsukei (biasa) dalam bentuk lampau atau verba - ta shita 'melakukan' menjadi shita noni 'padahal melakukan'. Data 4 jika diartikan secara leksikal menjadi: Padahal kemarin saya sudah berkali-kali mengirimkan pesan. Konjungsi noni pada kalimat tersebut berada di akhir kalimat sebagai kata sambung untuk menyatakan kekecewaan. Sehingga konjungsi yang tepat untuk kalimat tersebut yaitu 'padahal' Sedangkan secara kontekstual dalam konteks situasi dan objek pembicaraan, maka kalimat tersebut dapat diartikan: Mengapa kamu tidak membalas pesanku, padahal kemarin aku berkali-kali mengirimkan pesan. Pada kalimat ini, baik secara leksikal maupun kontekstual konjungsi noni memiliki arti "padahal" yang bermakna menyatakan kekecewaan karena konteksnya Yoshino merasa kecewa terhadap Yuusuke yang tidak membalas pesan-pesan yang ia kirimkan. Konjungsi noni yang digunakan pada kalimat ini ditujukan untuk mitra bicara/orang lain.

\subsection{Penggunaan Kuseni}

\subsubsection{Menyatakan Kritikan}

Data 5

なんで、一緒にバンドを組んでいるくせに。

Nande, isshouni bando wo kunderu kuseni.

'Kenapa, padahal (kalian) membentuk band bersama-sama.'

Situasi:

Yoshino ingin menemui Yuusuke di kelas. Tetapi ketika mencari ke arah bangku Yuusuke, Yoshino tidak menemukan Yuusuke. Kemudian Yoshino bertanya kepada Hideki namun Hideki mengatakan tidak tahu mengenai keberadaan Yuusuke. Yoshino merasa kesal kepada Hideki yang menurutnya tidak peduli tentang Yuusuke padahal mereka merupakan teman satu band. Yoshino mengkritik Hideki dengan mengatakan: "Nande, isshouni bando wo kunderu kuseni."

- Objek yang dibicarakan pada kalimat: Hideki dan Yuusuke yang merupakan teman satu band.

- Suasana hati pembicara: Kesal

Analisis: 
Pada data 5 konjungsi kuseni melekat pada verba - ru kunde iru 'membentuk' menjadi kunde iru kuseni. Konjungsi kuseni pada kalimat tersebut digunakan sebagai kata sambung untuk menyatakan kritikan yang diperkuat dengan kata isshouni 'bersama-sama' yang mengungkapkan ketidaksetujuan penutur terhadap ucapan dari mitra bicara. Data 5 jika diartikan secara leksikal menjadi: Kenapa, padahal (kalian) membentuk band bersama. Secara kontekstual berdasarkan situasi yang terjadi makna kalimat tersebut sama, dapat diartikan sebagai berikut: Kenapa kamu tidak tahu/peduli, padahal kalian membentuk band bersama. Konjungsi kuseni pada kalimat tersebut memiliki arti "padahal", yang menyatakan kritikan kepada orang lain. Dalam konteksnya, si pembicara (Yoshino) mengkritik Hideki yang tidak peduli keberadaan teman satu band-nya. Menurut Yoshino, seharusnya karena Hideki dan Yuusuke teman satu band, seharusnya Hideki mengetahui apa yang terjadi pada Yuusuke dan keberadaannya saat ini. Kalimat kritikan yang mengandung konjungsi kuseni ini ditujukan untuk ungkapan kepada mitra bicara/orang lain, dan suasana yang tersampaikan adalah perasaan kesal dan tidak setuju/tidak suka atas sikap si mitra bicara. Kritikan mirip dengan ketidaksetujuan seperti pada makna konjungsi noni. Akan tetapi konjungsi kuseni lebih digunakan untuk menggambarkan perasaan hati yang sangat kesal bahkan marah, dan ditujukan kepada orang lain.

\subsubsection{Menyatakan Hinaan atau Sindiran}

Data 6

うん。。もうんだ。彼女いるくせに

Un... moraunda. Kanojo iru kuseni.

'Hmm... (dia) menerima. Padahal ada (punya) pacar.'

Situasi:

Mizuno datang ke tempat kerja Yuusuke untuk menyampaikan titipan hadiah untuk Yuusuke dari Abe. Abe merupakan teman Mizuno yang mengaku kepada Mizuno bahwa ia menyukai Yuusuke. Yuusuke pun menerima hadiah tersebut. Mizuno merasa tidak menyukai sikap Yuusuke yang ternyata mau menerima hadiah dari Abe karena Mizuno tahu bahwa Yuusuke sudah punya pacar, tetapi tetap menerima hadiah dari wanita lain. Kemudian Mizuno pun menyindir Yuusuke: "Un... moraunda. Kanojo iru kuseni".

- Objek yang dibicarakan pada kalimat: Hadiah dari Abe yang diterima Yuusuke, padahal Yuusuke sudah punya pacar.

- Suasana hati pembicara: Merasa tidak suka, mengolok

Analisis:

Pada data 6 konjungsi kuseni melekat pada verba iru 'ada' menjadi iru kuseni. Konjungsi kuseni pada kalimat tersebut digunakan sebagai kata sambung untuk menyatakan sindiran yang diperkuat dengan kalimat kanojo iru 'mempunyai pacar' yang mengungkapkan ketidaksetujuan penutur terhadap perbuatan dari mitra bicara. Data 6 secara leksikal memiliki arti: Hmm... (dia) menerima. Padahal ada (punya) pacar. Secara kontekstual makna kalimat tersebut sama, yang kurang lebih dapat diartikan: Hmm... ternyata dia menerima hadiahnya (dari wanita lain), padahal dia sudah punya pacar. Konjungsi kuseni pada kalimat tersebut baik secara makna leksikal maupun secara makna kontekstual sama-sama memiliki arti "padahal", yang digunakan untuk mengungkapkan sindiran. Perbedaan sindiran dengan kritikan adalah sindiran disampaikan dengan nada atau suasana yang lebih mengolok, sedangkan kritikan lebih disampaikan dengan nada atau suasana yang kesal. Dalam konteks kalimat ini, si pembicara (Mizuno) menyindir mitra bicara (Yuusuke) yang menerima hadiah dari wanita lain padahal dia sudah punya pacar. Menurutnya itu bukan sikap yang baik maka ia menyindir mitra bicaranya tersebut. 


\subsubsection{Menyatakan Ketidaksukaan/Kekesalan}

Data 7

その勇気ないくせに。

Sono yuuki nai kuseni.

'Meskipun tidak ada keberanian.'

Situasi:

Mizuno sedang bersedih karena ibunya sedang sakit, dia pun berdiam diri di jembatan. Kemudian Yuusuke yang kebetulan sedang berjalan melewati jembatan bertemu dengan Mizuno yang sedang berdiam diri di jembatan, lalu Yuusuke menyapa dan dia mengobrol dengan Mizuno. Yuusuke mengkhawatirkan dan menanyakan keadaan Mizuno yang terlihat sedih. Karena tidak ingin terlihat sedih, Mizuno justru mengejek Yuusuke tentang dirinya yang pada hari sebelumnya memperoleh nilai terendah sehingga harus mengenakan ikat kepala bertuliskan "baka". Yuusuke mengatakan kepada Mizuno: Jadi kamu ingin mengejekku?.Mizuno memang bermaksud mengejek Yuusuke namun ia merasa tentunya tidak berani untuk mengejek karena dirinya pun pernah mengenakan ikat kepala tersebut yang menurutnya menyebalkan. Maka Mizuno pun berkata: "Sono yuuki nai kuseni".

- Objek yang dibicarakan pada kalimat: Ejekan Mizuno kepada Yuusuke tentang ikat kepala bertuliskan "baka"

- Suasana hati pembicara: Sebal, tidak menyukai

Analisis:

Pada data 7 konjungsi kuseni melekat pada negasi nai 'tidak' menjadi nai kuseni . Konjungsi kuseni pada kalimat tersebut digunakan sebagai kata sambung untuk menyatakan kritikan yang diperkuat dengan kalimat yuuki nai 'tidak berani. yang mengungkapkan ketidaksetujuan penutur terhadap ucapan dari mitra bicara. Data 7 memiliki makna leksikal Meskipun tidak ada keberanian. Secara kontekstual dapat diartikan: Ya, aku memang mengejek, meskipun sebenarnya aku tidak ada keberanian untuk mengejek tentang hal itu. Dalam kalimat ini, konjungsi kuseni memiliki arti "meskipun" yang digunakan untuk mengungkapkan ketidaksukaan terhadap sesuatu. Kalimat ini ditujukan untuk mitra bicara/orang lain, tetapi ketidaksukaan yang dimaksud ditujukan untuk objek pembicaraan.

\section{Simpulan}

Berdasarkan hasil analisis ditemukan bahwa kedua konjungsi, noni dan kuseni meskipun mempunyai persamaan dalam menyatakan pertentangan antara dua hal, yakni antara yang dipikirkan/diduga/seharusnya menurut pembicara dan fakta yang terjadi, noni lebih bersifat luas dan objektif. Noni dapat mengungkapkan perasaan negatif, seperti kekecewaan, kritikan, dan kekesan, namun juga dapat mengungkapkan perasaan netral maupun positif, seperti kekaguman. Sementara kuseni hanya digunakan untuk mengungkapkan perasaan negatif pembicara, seperti kritik, kesal, dan kecewa.

\section{Referensi}

Arino, S. (1998). Nihongo Bunkei Jiten. Kuroshio Shuppan.

Chandra, T. (2009). Nihongo no joshi. Evergreen.

Chino, N. (1991). All about particles Japan. Power of Japanese series.

Kawashima, S. A. (1999). A Dictionary of Japanese Particles. Kodansha Internasional. 
Machawan, A. E. R. (2016). Noni Dan Temo Dalam Serial Drama Jepang: Kajian Sintaksis Dan Semantis. S2 Thesis, UPI, Bandung.

Makino, S. (1994). The Dictionary of Intermediate Japanese Grammar. The Japan Times, Ltd.

Matsuura, K. (1994). Kamus Bahasa Jepang-Indonesia. Kyoto Sangyo University Press.

Moleong, L. J. (2010). Metodologi Penelitian Kualitatif. PT. Remaja Rosdakarya Offset.

Mulyadi, B. (1999). Analisis Konjungsi Dakara, Sorede, Shitagatte, Sonotame, Sonokekka dalam Bahasa Jepang. Skripsi, IKIP Bandung.

Putri, S. R. N. W. (2016). Analisis Makna Konjungsi Nagara, Noni, dan Kuseni Pada Kalimat Yang Menyatakan Pertentangan Dalam Bahasa Jepang. Skripsi, UPI Bandung.

Ramadhani, R. W. (2018). Analisis Kontrastif Konjungsi Noni Dalam Bahasa Jepang Dan Konjungsi Walaupun Dalam Bahasa Indonesia. Skripsi, UNDIP Semarang.

Saifudin, A. (2018). Konteks dalam Studi Linguistik Pragmatik. Lite: Jurnal Bahasa, Sastra, Dan Budaya, 14(1), 108-117. http://publikasi.dinus.ac.id/index.php/lite/article/view/2323/1462

Saifudin, A. (2019). Deiksis Bahasa Jepang dalam Studi Linguistik Pragmatik. Japanese Research on Linguistics, Literature, and Culture, 2(1), 16-35. https://doi.org/10.33633/jr.v2i1.3348

Saifudin, A. (2020). Implikatur Percakapan dalam Studi Linguistik Pragmatik (Conversational Implicature in Pragmatic Linguistic Studies). Jalabahasa, 16(1), 15-24. https://jalabahasa.kemdikbud.go.id/index.php/jalabahasa/article/view/423

Sari, I. G. A. M. I. N., Antartika, I. K., \& Suartini, N. N. (2017). Analisis Makna Kontrastif pada Konjungsi Ga dan Demo dalam Cerpen Kusa Suberi Karya Nagi Keishi. Jurnal Pendidikan Bahasa Jepang Undiksha, 3(3), 420-430. https://doi.org/http://dx.doi.org/10.23887/ipbj.v3i2.12144

Sudjianto. (1996). Gramatika Bahasa Jepang Modern Seri A. Kesaint Blanc. 